\title{
SILVER NANOPARTICLES DOPED SLAKED LIME AS ADSORBENT FOR THE REMOVAL OF BASIC DYES
}

\author{
J. Sheeja ${ }^{1}$, K. Sampath ${ }^{2, *}$ and R.Manivel ${ }^{3}$ \\ ${ }^{1}$ Department of Chemistry, Sri Ramakrishna Engineering College, \\ Coimbatore-641022, Tamil Nadu, India. \\ ${ }^{2}$ Department of Science and Humanities, Chemistry Division, Kumaraguru College of \\ Technology, Coimbatore-641049, Tamil Nadu, India. \\ ${ }^{3}$ Department of Mechanical Engineering, Kumaraguru College of Technology, \\ Coimbatore-641049, Tamil Nadu, India. \\ *E-mail : sampathchemistry@ gmail.com
}

\begin{abstract}
A new eco-friendly green synthesized silver nanoparticles doped slaked lime was developed as an adsorbent for the removal of basic dyes from aqueous solution. Silver nanoparticles were synthesized through a green route using pomegranate peel and doped with slaked lime. Its applicability in removing basic green 4 dye from aqueous solution was evaluated in a batch process. The effect of control variables such as initial dye concentration, adsorbent dose, $\mathrm{pH}$, agitation time and temperature on the removal of basic green 4 by silver doped slaked lime was analyzed. The experimental data were fitted to classical isotherms such as Langmuir, Freundlich and Temkin. The reaction kinetics was examined by interpreting the equilibrium data using pseudo first order, pseudo-second order and intraparticle diffusion equations. The thermodynamic data were examined for feasibility in the potential application on an industrial scale. These studies have proved that rate of adsorption of basic green 4 is excellent and rapid on silver nanoparticles doped slaked lime in which silver nanoparticles induce a local dipole field that enhances adsorption of dye molecules on a rapid scale.
\end{abstract}

Keywords: Silver nanoparticles, green synthesis, pomegranate peel, slaked lime, basic green 4

( ) RASĀYAN. All rights reserved

\section{INTRODUCTION}

Dyes and paints are widely used in industries like textiles, paper and pulp, plastics, cosmetics, food, tanneries, pharmaceuticals, petroleum refineries etc. The effluents discharged from them contain heavy loads of mixed colors that look unpleasant and reflect toxicity to aquatic life. One of the toxic dye that is commonly used as a direct dye on silk, cotton, wool, jute, leather and aquaculture is basic green $4 .{ }^{1,2}$ Living organisms exposed to this dye suffer from carcinogenic, mutagenic, teratogenic issues and chromosomal fractures. ${ }^{3}$ The self-degradation of dyes has always been challenging. Moreover, synthetic dyes are more stable having symmetric and complex aromatic structure. Despite many conventional techniques adopted for wastewater treatment such as flocculation, sedimentation ultrafiltration and color irradiation, their technical and economical constraints prevent them from applying to wastewater. In this juncture, adsorption methods which is cost effective and environment-friendly have always proved to be the best in wastewater treatment.

Several biomaterial and non-biomaterial adsorbents were used in past years, for example, soybean hull, coconut shell, rice husk, zeolites and clay. ${ }^{4-8}$ Yet an efficient adsorbent for an industrial scale is still in demand.On the other hand, Calcium hydroxide has been used as a cost-effective adsorbent for the removal of indigo carmine dye and has reported effective adsorption in 50 minutes time. ${ }^{9}$ These observations have led to the invention of doping of silver nanoparticles into the adsorbent with slaked lime. This diverted our interest in exploring a new adsorbent through a green route synthesis of silver nanoparticles and doped with slaked lime for the basic green 4 dye removal. Further, the results were evaluated with respect to $\mathrm{pH}$, adsorbent dose, concentration, agitation time and kinetics.

Rasayan J. Chem., 12(1), 262-271(2019)

http://dx.doi.org/10.31788/RJC.2019.1215002

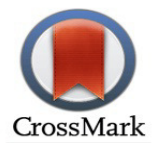


RASĀYAN J. Chem.

Vol. 12 | No. 1 |262 - 271| January - March | 2019

\section{EXPERIMENTAL}

\section{Material and Methods}

Silver nitrate, Slaked lime, basic green 4 dye (AR Grade) were purchased from Merck, India and Loba Chemie Ltd. Mumbai respectively and used without purification. Equilibrium concentrations were obtained from a calibration curve using UV/vis spectrophotometer (Analytik/ Jena, Germany). Fourier Transform-Infrared spectrum was recorded on Bruker ranging in 4000-400 $\mathrm{cm}^{-1}$, and Scanning Electron micrograph was obtained from Zeiss.

\section{Preparation of Nano Adsorbent}

The peels of pomegranate were collected, washed and sun-dried well. It was powdered using a grinder and the powder was extracted with water and boiled at $100{ }^{\circ} \mathrm{C}$ for about 15 minutes. ${ }^{10}$ The aliquot was separated by centrifuging the mixture at $2000 \mathrm{rpm}$ for half an hour to get a clear solution of peel extract. $10 \mathrm{mM}$ silver nitrate solution was prepared and added in 2:1 ratio with pomegranate peel extract and intermittently stirred using magnetic stirrer for $8 \mathrm{~h}$ till the brown colored precipitate was obtained. The samples were drawn at regular intervals and the absorbance was noted that confirm the formation of silver nanoparticles. The mixture was mixed in 1.5:2 ratio with slaked lime. The impregnated residue formed is separated by centrifugation at the rate of $2000 \mathrm{rpm}$ and dried in the vacuum desiccator. The doped sample was stored in an airtight brown sample bottles for adsorption studies.

\section{Preparation of Adsorbate Solution}

The stock solution of basic green 4 dye was prepared by dissolving $100 \mathrm{mg}$ of the dye in $1000 \mathrm{~mL}$ of double distilled water. A set of standard dye concentrations ranging from $1.076 \times 10^{-4} \mathrm{M}$ to $1.076 \mathrm{X} 10^{-3}$ $\mathrm{M}$ was prepared. The $\mathrm{pH}$ of the basic green 4 solutions was varied from 1.0-12.0 using decimolar solutions of $\mathrm{HCl}$ and $\mathrm{NaOH}$ to study the effect of $\mathrm{pH}$ on adsorption of dye onto silver nanoparticle doped slaked lime (SDSL).

\section{Adsorption Studies}

The efficiency of adsorption was evaluated at different initial dye concentration (10-100 ppm), $\mathrm{pH}$ (3-9), dose (0.01-0.07 g), time (5-30 mins) and temperature $\left(30-45^{\circ} \mathrm{C}, 303-318 \mathrm{~K}\right)$ and the precise condition for maximum removal of basic green 4 dye from aqueous solution was optimized. Kinetic experiments were performed to determine the rate of adsorption of basic green 4 dye onto SDSL. The feasibility of the adsorption reaction was analyzed at predetermined equilibrium conditions. The equilibrium absorption maximum was recorded at $615 \mathrm{~nm} .{ }^{11}$ Batch mode experiments were performed against varied parameters and the equilibrium concentrations were obtained from the calibration curve. The amount of adsorbed dye on SDSL at equilibrium was calculated from the equation (1). ${ }^{12}$

$$
\mathrm{q}_{\mathrm{e}}=\frac{\mathrm{C}_{0}-\mathrm{C}_{\mathrm{e}}}{\mathrm{W}} \times \mathrm{V}
$$

Where $\mathrm{C}_{0}\left(\mathrm{mgL}^{-1}\right)$ is the initial dye concentration, $\mathrm{C}_{\mathrm{e}}\left(\mathrm{mgL}^{-1}\right)$ is the dye concentration at equilibrium, $\mathrm{V}$ is the test volume of the dye solution (L) and $\mathrm{W}$ is the weight of operating adsorbent $(\mathrm{g})$.

The percentage removal of the dye by SDSL was calculated using equation (2):

$$
\text { Removal efficiency, } \%=\frac{\left(\mathrm{C}_{0}-\mathrm{C}_{\mathrm{e}}\right)}{\left(\mathrm{C}_{0}\right)} * 100
$$

\section{Isotherm and Kinetic Studies}

The physical interaction mechanism during adsorption was understood from classical isotherms such as Langmuir, Freundlich and Temkin models. The adsorption rate of the dye to SDSL was evaluated using 
pseudo first order and pseudo second order equations and the nature of adsorption was understood using the intraparticle diffusion model.

\section{Langmuir Isotherm}

$$
\mathrm{C}_{\mathrm{e}} / \mathrm{q}_{\mathrm{e}} \quad=\mathrm{C}_{\mathrm{e}} / \mathrm{q}_{\mathrm{m}}+1 / \mathrm{K}_{\mathrm{L}} \mathrm{q}_{\mathrm{m}}
$$

Freundlich Isotherm

$$
\log \mathrm{q}_{\mathrm{e}}=\log \mathrm{K}_{\mathrm{F}}+(1 / \mathrm{n}) \log \mathrm{C}_{\mathrm{e}}
$$

\section{Temkin Isotherm}

$$
\mathrm{q}_{\mathrm{e}}=\frac{\mathrm{RT}}{\mathrm{b}} \ln \left(\mathrm{A}_{\mathrm{T}}+\mathrm{Ce}\right)
$$

Where, $\mathrm{q}_{\mathrm{m}}$ is the monolayer adsorption parameter

$\mathrm{K}_{\mathrm{L}}$ is Langmuir constant

$\mathrm{n}$ is Freundlich constant

$\mathrm{K}_{\mathrm{F}}$ is Freundlich coefficient

$\mathrm{A}_{\mathrm{T}}$ is Temkin binding constant $(\mathrm{L} / \mathrm{g})$

$\mathrm{b}$ is Temkin constant

\section{Pseudo First Order Equation}

$$
\ln \left(\mathrm{q}_{\mathrm{e}}-\mathrm{q}_{\mathrm{t}}\right)=\ln \mathrm{q}_{\mathrm{e}}-\mathrm{k}_{1} \mathrm{t}
$$

\section{Pseudo Second Order Equation}

$$
\frac{\mathrm{t}}{\mathrm{q}_{\mathrm{t}}}=\frac{1}{\mathrm{k}_{2} \mathrm{q}_{\mathrm{e}}{ }^{2}}+\frac{\mathrm{t}}{\mathrm{qe}}
$$

\section{Intraparticle Diffusion}

$$
\mathrm{q}_{\mathrm{t}}=\mathrm{k}_{\mathrm{i}} \mathrm{t}^{1 / 2}+\mathrm{C}
$$

Where $\mathrm{q}_{\mathrm{t}}$ is the amount of dye absorbed at time $\mathrm{t}$

$\mathrm{k}_{1}$ is the reaction rate constant in $\mathrm{s}^{-1}$

$\mathrm{k}_{2}$ is the pseudo-second-order rate constant

$\mathrm{k}_{\mathrm{i}}$ is the intraparticle diffusion rate constant

$\mathrm{C}$ is the intercept

\section{RESULTS AND DISCUSSION}

Silver nanoparticle doped slaked lime was characterized as follows:

\section{Infrared Spectra}

A peak at $3555 \mathrm{~cm}^{-1}$ and $2925 \mathrm{~cm}^{-1}$ corresponds to $\mathrm{OH}$ stretching of water molecules that proves the deliquescent nature of slaked lime. ${ }^{13}$ A peak at $2854 \mathrm{~cm}^{-1}$ shows the presence of $-\mathrm{CH}_{2}$ - asymmetric stretching. A sharp band at $1665 \mathrm{~cm}^{-1}$ indicates $\mathrm{C}=\mathrm{O}$ stretching. Some important peaks at 1622,1510 , 1341 and $1055 \mathrm{~cm}^{-1}$ are the characteristic peak of silver nanoparticles. ${ }^{14} \mathrm{~A}$ band at $754 \mathrm{~cm}^{-1}$ shows the stretch of silver nanoparticles.

\section{SEM Analysis}

The surface morphology of SDSL and SDSL - BG4 is given by Fig.-1. Figure-1a indicates the bulky sized slaked lime particles with a white coat of silver nanoparticles providing a larger surface area for 
adsorption of dye. ${ }^{15}$ Figure- $1 \mathrm{~b}$ indicates the dye adsorbed slaked lime where the dye molecules have got attracted to SDSL thereby showing a populated, rough and flaked surface.

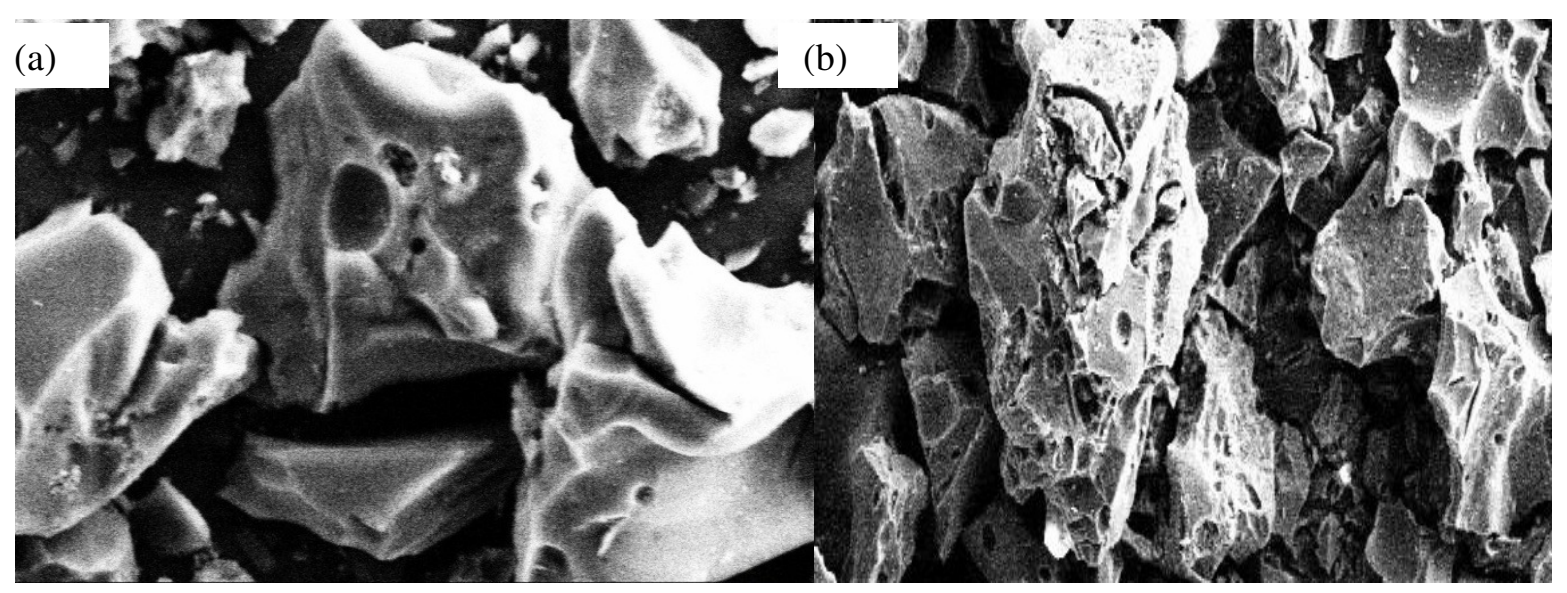

Fig.-1:(a) SEM Micrograph of Slaked Lime Containing Silver Nanoparticles and (b) SEM Micrograph of BG4 Dye

\section{Effect of $\mathbf{p H}$}

Adsorbed on SDSL

The influence of $\mathrm{pH}$ on the proportionate removal of basic green 4 by SDSL was examined at $\mathrm{pH}$ 3-9 and is given by the Fig.-2. The equilibrium data obtained was plotted and show that efficient removal of the dye of $99.9 \%$ was at $\mathrm{pH} 6.5$. This observation ascribe to anionic charge density of the surface sites on slaked lime due to hydroxides that attract the positive quaternary ammonium points on the dye thereby facilitating attraction of the dye onto SDSL sites. ${ }^{16}$ Further, the inset of silver nanoparticles in the bulk of slaked lime enhances the dye uptake due to the difference in potential of silver nanoparticles and BG4 dye and increase in dipole field effect of the silver nanoparticles. ${ }^{17-18}$ However, very low $(<3)$ and high $\mathrm{pH}$ (>8.5) caused instability to the dye.



Fig.-2: Influence of pH on BG4 Dye Removal

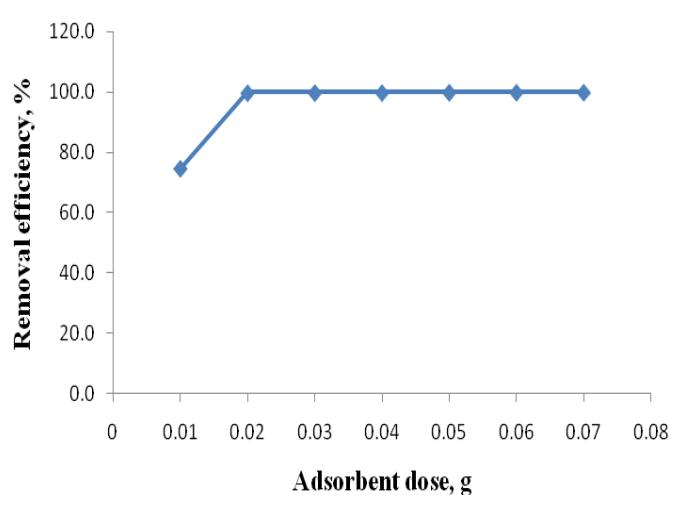

Fig.-3: Influence of Adsorbent Dose on BG4 Dye Removal

\section{Effect of SDSL dose}

Figure-3 shows the influence of SDSL dose on the adsorption percentage of basic green 4 from the solution. It could be noted that, as the adsorbent dose increased, more reactive sites are available for dye interaction and thus enhancing the rate of dye diffusion onto the SDSL. ${ }^{19}$ Moreover, the presence of silver nanoparticles impregnated in slaked lime has increased the chances of inter ionic effect thus producing rapid adsorption. Nevertheless, this behavior was not steady because equilibrium was reached at $0.05 \mathrm{~g}$ SDSL dose between the dye inside and outside the solution yet showing maximum dye adsorption of 99.8 $\% .^{20}$ Thus $0.05 \mathrm{~g}$ of SDSL was fixed at $\mathrm{pH} 6.5$ as an optimum dose for further studies.

Various standard concentrations of the dye solution were fixed to determine the higher concentration limit of dye removal. The removal efficiency was studied as the function of initial dye concentration varied 
between 10-100 mg/l. Figure - 4 indicates the amount of dye adsorbed by SDSL with the rate of change in initial dye concentration. There is an increasing adsorption behavior proportionate to the dye concentration. However, when the charge density on the surface of SDSL runs down, no further electrostatic attraction for the dye takes place thus attaining stability. ${ }^{21}$

\section{Effect of Initial Dye Concentration}

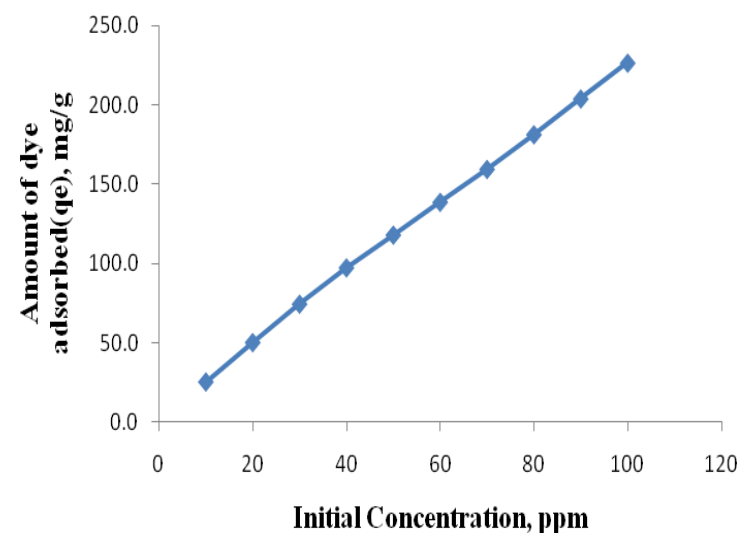

Fig.-4: Influence of Concentration on Removal of Dye

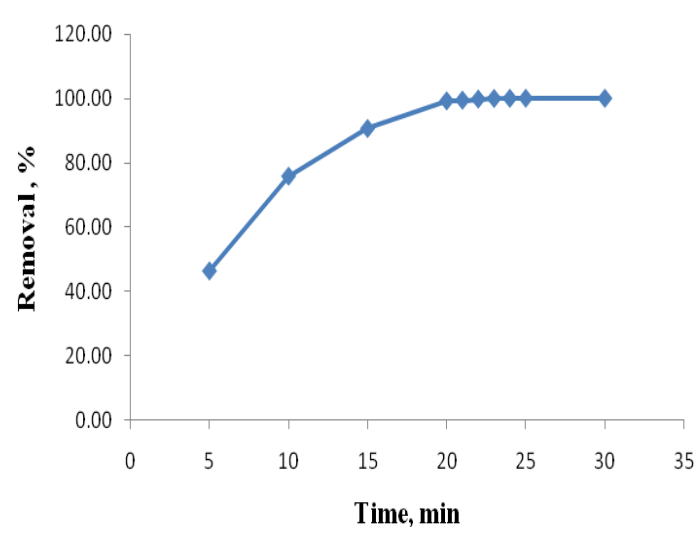

Fig.-5: Influence of Operating Time on Removal of Dye

\section{Effect of Operating Time}

The adsorption of dye on SDSL was evaluated at regular time interval varying from 5-30 minutes. Figure - 5 shows adsorption at a different time interval. The plot infers that the attraction of the dye towards SDSL takes time delay due to a repulsive interaction between charges as they come altogether closer to each other. Gradually charge distribution takes place which makes the BG4 dye get attracted towards SDSL. It is then followed by rapid adsorption due to the availability of silver nanoparticles thus removing $99.9 \%$ of the dye within 25 minutes. On contrary, earlier reports on the adsorption of indigo carmine dye using calcium hydroxide where the rapid electrostatic attraction is expected has reported that effective removal consumed 50 mins. ${ }^{9}$

\section{Effect of Temperature}

The rate of adsorption of basic green 4 dye on SDSL was evaluated in terms of temperature such as 303 $\mathrm{K}, 308 \mathrm{~K}, 313 \mathrm{~K}$ and $318 \mathrm{~K}$ as shown in Figure - 6. It was observed that there is no remarkable change in removal \% of the dye by SDSL with a change in temperature. This is due to the fact that adsorption of BG4 dye onto SDSL is purely based on electrostatic interaction between charges and metal-dye interionic interaction between silver nanoparticles and the dye and not on the influence of the temperature. ${ }^{22}$ On the other hand, the earlier literature has reported that adsorption of indigo carmine acid dye using calcium hydroxide increased with the increase in temperature as shown in Figure - 7 thus obeying the laws of chemical kinetics. ${ }^{9}$ However, a slight increase in removal \% of the dye with temperature indicates the dynamic nature of adsorption.

\section{Isotherm Studies}

The equilibrium data were analyzed with various isotherm models such as Langmuir, Freundlich and Temkin model to examine the nature of BG4 adsorption onto SDSL. The Langmuir plot is obtained between $\mathrm{C}_{\mathrm{e}} / \mathrm{q}_{\mathrm{e}}$ vs. $\mathrm{C}_{\mathrm{e}}$ from Table-1 as shown in Fig.-8 from which the slope and intercept is determined. The isotherm constants $\mathrm{q}_{\mathrm{m}}$ and $\mathrm{K}_{\mathrm{L}}$ are thus calculated (Table-2) that predicts whether BG4 dye adsorption onto SDSL follows monolayer or multilayer route.

The regression line shows a correlation of $\mathrm{R}^{2}=0.96$ with the equilibrium data thus deviating from unity. This infers that monolayer adsorption route for BG4 dye on SDSL is less favorable. Moreover, the 
RASĀYAN J. Chem.

Vol. 12 | No. 1 |262 - 271| January - March | 2019

dimensionless parameter $\mathrm{R}_{\mathrm{L}}$ is calculated using equ.- 9 and the values are found to be close to 1.0 which indicates non feasibility of the isotherm. ${ }^{23}$

$$
\mathrm{R}_{\mathrm{L}}=1 /\left(1+\mathrm{K}_{\mathrm{L}} \times \mathrm{C}_{\mathrm{e}}\right)
$$



Fig.-6: Influence of Temperature on Removal \%

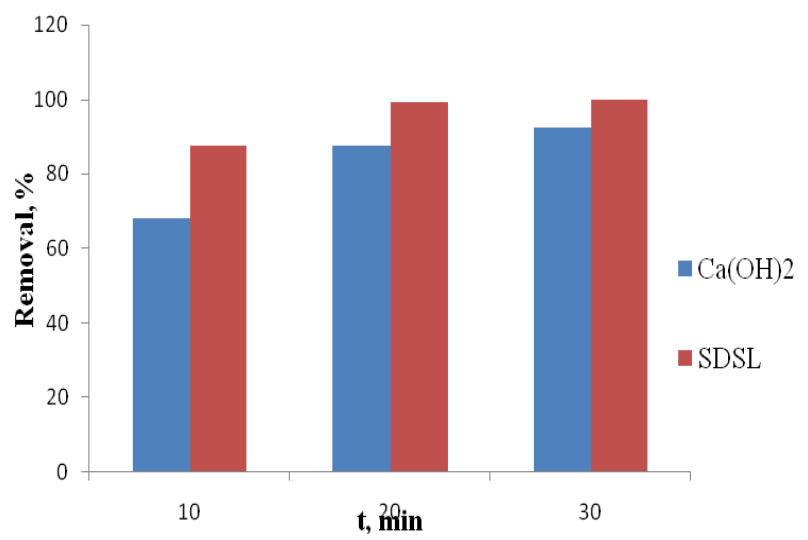

Fig.-7 Removal \% by $\mathrm{Ca}(\mathrm{OH})_{2}$ and SDSL of BG4 Dye

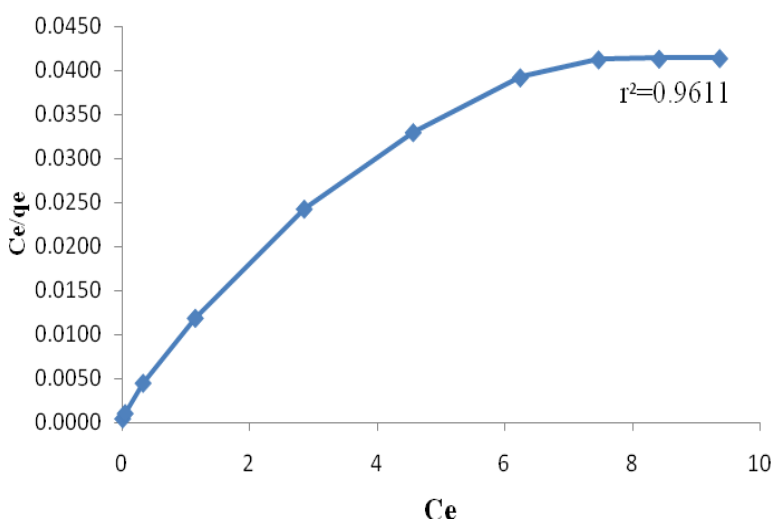

Fig.-8: Langmuir Isotherm Model



Fig.-9: Freundlich Isotherm Model



Fig.-10: Temkin Isotherm Model

Table - 1: Equilibrium Parameters of BG4 Adsorption Using SDSL for Isotherm Studies at $303 \mathrm{~K}$

\begin{tabular}{c|c|c|c|c|c|c}
\hline $\mathrm{C}_{0}$ & $\mathrm{C}_{\mathrm{e}}$ & $\mathrm{q}_{\mathrm{e}}$ & $\mathrm{C}_{\mathrm{e}} / \mathrm{q}_{\mathrm{e}}$ & $\log \mathrm{C}_{\mathrm{e}}$ & $\log \mathrm{q}_{\mathrm{e}}$ & $\ln \mathrm{C}_{\mathrm{e}}$ \\
\hline$(\mathrm{mg} / \mathrm{l})$ & $(\mathrm{mg} / \mathrm{l})$ & $(\mathrm{mg} / \mathrm{g})$ & & & & \\
\hline & & & & & & \\
\hline 10 & 0.01 & 24.98 & 0.0004 & -2 & 1.4 & -4.606 \\
\hline
\end{tabular}


RASĀYAN J. Chem.

Vol. 12 | No. 1 |262 - 271| January - March | 2019

\begin{tabular}{c|c|c|c|c|c|c}
\hline 20 & 0.05 & 49.88 & 0.001 & -1.30 & 1.70 & -3.0 \\
\hline 30 & 0.33 & 74.18 & 0.0044 & -0.48 & 1.87 & -1.11 \\
\hline 40 & 1.15 & 97.13 & 0.011 & 0.061 & 1.99 & 0.139 \\
\hline 50 & 2.86 & 117.85 & 0.024 & 0.46 & 2.07 & 1.051 \\
\hline 60 & 4.57 & 138.58 & 0.003 & 0.66 & 2.14 & 1.52 \\
\hline 70 & 6.25 & 159.38 & 0.0392 & 0.80 & 2.2 & 1.83 \\
\hline 80 & 7.48 & 181.3 & 0.0413 & 0.87 & 2.26 & 2.01 \\
\hline 90 & 8.43 & 203.93 & 0.0413 & 0.93 & 2.31 & 2.132 \\
\hline 100 & 9.38 & 226.55 & 0.0414 & 0.97 & 2.36 & 2.24 \\
\hline
\end{tabular}

Freundlich isotherm model was applied to understand the adsorbate-adsorbent interaction. Figure-9 shows the plot between $\log \mathrm{q}_{\mathrm{e}}$ vs. $\log \mathrm{C}_{\mathrm{e}}$ (Table-1) from which Freundlich constants $\mathrm{n}$ and $\mathrm{K}_{\mathrm{F}}$ are calculated in Table - 2. The plot shows a high correlation with the data whose $\mathrm{R}^{2}=0.99$. The dimensional constant $1 / \mathrm{n}$ $=0.2870$ confirms the possibility of high intensity of multilayer adsorption. Earlier literature has reported that the value of $1 / \mathrm{n}$ between $0.1-0.5$ indicates good adsorption, $0.5-1.0$ indicates moderate adsorption and $1 / \mathrm{n}>1$ indicate the possibility of weak adsorption. ${ }^{24}$

Temkin isotherm illustrates the distribution of adsorbate on the adsorbent surface as the function of binding energy. ${ }^{25}$ The Temkin plot of $\operatorname{lnC}_{\mathrm{e}} \mathrm{vs}$. $\mathrm{q}_{\mathrm{e}}$ (Table-1) is shown in Figure - 10. It is inferred that the plot is a nonlinear curve and the equilibrium data did not fit in the Temkin equation $\left(\mathrm{R}^{2}=0.91\right)$. The constants are given in Table- 2 .

Table-2: Isotherm Constants for BG4 Adsorption Using SDSL at $303 \mathrm{~K}$

\begin{tabular}{c|c|c|c|c|c|c|c|c}
\hline \multicolumn{3}{|c|}{ Langmuir } & \multicolumn{3}{c|}{ Freundlich } & \multicolumn{3}{c}{ Temkin } \\
\hline $\mathrm{q}_{\mathrm{m}}$ & $\mathrm{K}_{\mathrm{L}}$ & $\mathrm{R}^{2}$ & $1 / \mathrm{n}$ & $\mathrm{K}_{\mathrm{F}}$ & $\mathrm{R}^{2}$ & $\mathrm{~A}_{\mathrm{T}}$ & $\mathrm{b}$ & $\mathrm{R}^{2}$ \\
\hline 200 & 1.02 & 0.961 & 0.287 & 100 & 0.987 & 114.8 & 98.02 & 0.919 \\
\hline
\end{tabular}

\section{Adsorption Kinetics}

The reaction kinetics of BG4 adsorption on SDSL was evaluated using pseudo-first and second order rate equations and the mechanism was understood from intraparticle diffusion model. ${ }^{26}$ Pseudo first order plot is given by Fig.-11 which indicates that adsorption did not follow pseudo-first order kinetics whereby the correlation coefficient being $\mathrm{R}^{2}=0.8747$ (Table-3).



Fig.-11: Pseudo First Order Plot



Fig.-12: Pseudo Second Order Plot

Pseudo-first order equation was not obeyed in the adsorption of indigo carmine dye using calcium hydroxide rather. Figure-12 shows the pseudo-second order plot that illustrates an effective chemical interaction involving charge transfer between adsorbate and adsorbent. The data fits well with the graph showing a straight line and the value of $\mathrm{R}^{2}=0.9922$ (Table-3). Intraparticle diffusion model explains the penetration of adsorbate into the matrix of the adsorbent. The intraparticle plot is shown in Fig.-13. The 
RASĀYAN J. Chem.

Vol. 12 | No. 1 |262 - 271| January - March | 2019

plot shows a curve like a bend throughout at all concentrations. This proposes that adsorption of BG4 by SDSL did not follow intra particle diffusion at all and is purely driven by electrostatic adsorbateadsorbent interaction or charge transfer between adsorbate and adsorbent.

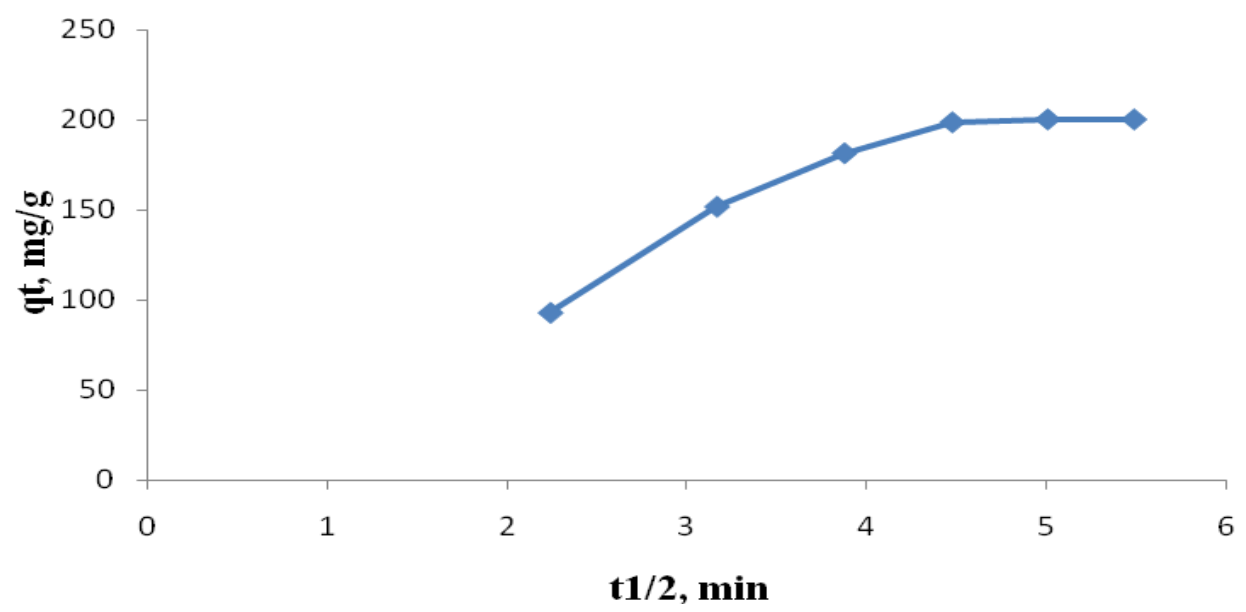

Fig.-13: Intra Particle Diffusion Plot

Table-3: Kinetic Constants for BG4 Adsorption Using SDSL at $303 \mathrm{~K}$

\begin{tabular}{c|c|c|c|c|c|c|c|c}
\hline \multicolumn{2}{c|}{ Pseudo $1^{\text {st }}$ Order } & \multicolumn{3}{c|}{${\text { Pseudo } 2^{\text {nd }} \text { Order }}$} & \multicolumn{3}{c}{ IPD } \\
\hline $\mathrm{q}_{\mathrm{e}(\exp )}$ & $\mathrm{q}_{\mathrm{e}(\mathrm{cal})}$ & $\mathrm{k}_{1}$ & $\mathrm{R}^{2}$ & $\mathrm{q}_{\mathrm{e}(\mathrm{cal})}$ & $\mathrm{k}_{2}$ & $\mathrm{R}^{2}$ & $\mathrm{ki}$ & $\mathrm{R}^{2}$ \\
\hline 200 & 13.8 & 0.1 & 0.88 & 250 & 0.001 & 0.9922 & 32.8 & 0.930 \\
\hline
\end{tabular}

\section{Thermodynamics of Adsorption}

The thermodynamics of adsorption of BG4 by SDSL were investigated using Van't Hoff plot, Fig.-14 and from the values of $\Delta \mathrm{G}$, free energy change, $\Delta \mathrm{H}$, enthalpy change and $\Delta \mathrm{S}$, entropy change. The value of $\Delta \mathrm{G}^{0}$ was calculated using equation 10 as:

$$
\Delta \mathrm{G}^{0}=-\mathrm{RT} \ln \mathrm{K}_{\mathrm{L}}
$$

Where $\mathrm{K}_{\mathrm{L}}$ is the equilibrium constant given by $\mathrm{q}_{\mathrm{e}} / \mathrm{C}_{\mathrm{e}}{ }^{27}$ Other thermodynamic parameters such as $\Delta \mathrm{H}$ and $\Delta \mathrm{S}$ are calculated from the intercept and slope of Van't Hoff plot respectively.

Table-4: Thermodynamic Variables for BG4 Adsorption on SDSL

\begin{tabular}{c|c|c|c}
\hline Temperature, $\mathrm{K}$ & $\Delta \mathrm{G}$ & $\Delta \mathrm{H}$ & $\Delta \mathrm{S}$ \\
\hline & $\mathrm{kJ} \mathrm{mol}^{-1}$ & $\mathrm{~kJ} \mathrm{~mol}^{-1}$ & $\mathrm{~kJ} \mathrm{~mol}^{-1} \mathrm{~K}^{-1}$ \\
\hline 303 & -3.33 & & \\
\hline 308 & -3.38 & -1.76 & 10.98 \\
\hline 313 & -3.44 & & \\
\hline 318 & -3.49 & & \\
\hline
\end{tabular}

Table-4 gives the negative values for free energy and enthalpy indicating that adsorption progresses spontaneously and decreasing values at the higher temperature indicated exothermic nature of adsorption. The higher positive value of $\Delta \mathrm{S}$ proves more feasibility of the reaction.

\section{CONCLUSION}

The effectiveness of the BG4 removal using silver nanoparticles doped slaked lime was studied under different conditions of initial dye concentrations, $\mathrm{pH}$, time, dose and temperature. A fairly very high removal $(99.96 \%)$ was achieved for higher initial concentrations $(80 \mathrm{ppm})$, basic $\mathrm{pH} 6.5$, lesser adsorbent dose $(50 \mathrm{mg})$, less contact time $(25 \mathrm{~min})$ and utmost room temperature. This is due to the fact that 
RASĀYAN J. Chem.

Vol. 12 | No. 1 |262 - 271| January - March | 2019

adsorption of BG4 dye onto SDSL is based on electrostatic interaction between charges and the presence of silver nanoparticles with slaked lime enhances the adsorption of the dye due to the difference in potential of silver nanoparticles and BG4 dye. Isotherm studies proved multilayer adsorption due to increase in dipole field effect of the silver nanoparticles resulting in a greater degree of accumulation of dye on SDSL. This resulted in rapid adsorption following pseudo-second-order kinetics. Further, the mechanism of BG4 adsorption on SDSL was governed by electrostatic interaction of charges between the dye and SDSL. The thermodynamic variables such as free energy, enthalpy and entropy values confirmed the spontaneity and feasible exothermic reaction at an ordinary temperature between the adsorbate and the adsorbent. Thus silver nanoparticle doped slaked lime shall be used as an effective and rapid adsorbent for the removal of basic green 4 dye



Fig.-14: Van't Hoff Thermodynamic Model

ACKNOWLEDGMENT

Authors are grateful to the chemistry department of Sri Ramakrishna Engineering College and Kumaraguru College of Technology for the facilities rendered and Department of Nanoscience and Technology, Sri Ramakrishna Engineering College for the characterization facilities.

\section{REFERENCES}

1. M. Kosha, O. Farhadian, S. Dorafshan and N.M. Soofiani, J. Environ. Stud., 40, 163(2014), DOI: 10.1016/j.jtice.2012.10.009

2. A.S. Sartape, A.M. Mandhare, V.V. Jadhav, P.D. Raut, M.A. Anuse and S.S. Kolekar, Arab. J. Chem., 10, 3229(2017), DOI:10.1016/j.arabjc.2013.12.019

3. S. Srivastava, R. Sinha and D. Roy, Aquat. Toxicol., 66, 319(2004), DOI:10.1016/j.aquatox.2003.09.008

4. L. Jia and T. Tianwei, Chinese J. Chem. Eng., 19, 334(2011), DOI:10.1016/s1004-9541(11)60173-0

5. C. Song, S. Wu, M. Cheng, P. Tao, M. Shao and G. Gao, Sustainability-Basel, 6, 86(2014), DOI:10.3390/su6010086

6. M. Ajmal and R. Ahmad, Bioresource Technol.,86,147(2003), DOI:10.1016/S0960-8524(02)00159-1

7. R.I. Yousef, B. El-Eswed and A.H. Al-Muhtaseb, Chem. Eng. J., 171, 1143(2011), DOI:10.1016/j.cej.2011.05.012

8. W.T. Tsai, Y.M. Chang, C.W. Lai and C.C. Lo, Appl. Clay Sci., 29, 149(2005), DOI:10.1016/j.clay.2004.10.004

9. T.N. Ramesh, D.V. Kirana, A. Ashwini, T.R. Manasa, J. Saudi Chem. Soc., 21, 165(2015), DOI:10.1016/j.jscs.2015.03.001

10. S. Phongtongpasuk and S. Poadang, Adv. Mat. Res., 1131, 227(2016), DOI:10.4028/www.scientific.net/AMR.1131.227 
RASĀYAN J. Chem.

Vol. 12 | No. 1 |262 - 271| January - March | 2019

11. M. Rajabi, B. Mirza, K. Mahanpoor, M. Mirjalili, F. Najafi, O. Moradi, H. Sadegh, R.S. Ghoshekandi, M. Asif, I. Tyagi, S. Agarwal, V.K. Gupta, J. Ind. Eng. Chem., 34, 130(2016), DOI:10.1016/j.jiec.2015.11.001

12. D. Pathania and P. Singh, Arab. J. Chem., 10, S1445(2017), DOI:10.1016/j.arabjc.2013.04.021

13. S. Mopoung, P. Moonsri, W. Palas and S. Khumpai, The Scientific World Journal, 2015, ID 415961 (2015), DOI: $10.1155 / 2015 / 415961$

14. S. Roy, T. Mukherjee, S. Chakraborty and T. Kumar das, Dig. J. Nanomater. Bios., 8, 197(2013).

15. V. Tamilselvi and K.V. Radha, Korean J. Chem. Eng., 34, 1801(2017), DOI:10.1007/s11814-0170075-4

16. N. Pramanpol and N. Nitayapat, Kasetsart J. (Nat. Sci.), 40, 192(2006).

17. D.A. Vishenkova, E.I. Korotkova, V.A. Sokolova and B. Kratochvil, Procedia Chem., 15, 109(2015), DOI:10.1016/j.proche.2015.10.017

18. E. Sumesh, M.S. Bootharaju, Anshup and T. Pradeep, J. Hazard. Mater, 189, 450(2011), DOI:10.1016/j.jhazmat.2011.02.061

19. R. Mahalakshmi, L. Ravikumar and K. Rathina, Rasayan J.Chem , 10, 286(2017), DOI: 10.7324/RJC.2017.1011633

20. L. Liu, Y. Lin, Y. Liu, H. Zhu and Q. He, J. Chem. Eng. Data, 58, 2248(2013), DOI: $10.1021 / \mathrm{je} 4003543$

21. N.Gopal and M. Asaithambi, Rasayan J.Chem, 8, 279(2015).

22. O. Allahdin, M. Wartel, J. Mabingui and A. Boughriet, Am. J. Analyt. Chem., 6, 11(2015), DOI:10.4236/ajac.2015.61002

23. M. El Haddad, R. Slimani, R. Mamouni, S. El Antri and S. Lazar, J. Assoc. Arab Univ. Basic Appl. Sci., 14, 51(2013), DOI:10.1016/j.jaubas.2013.03.002

24. N. C. Joshi and V. Bahuguna, Rasayan J. Chem., 11, 142(2018), DOI:10.7324/RJC.2018.1112008

25. A.O. Dada, A.P. Olalekan, A.M. Olatunya and O. Dada, IOSR J. App. Chem., 3, 38(2012), DOI: $10.9790 / 5736-0313845$

26. L. Largitte and R. Pasquier, Chem. Eng. Res. Des., 109, 495(2016), DOI: $10.1016 /$ j.cherd.2016.02.006

27. S. Rani and D. Sud, Plant Soil Environ., 61, 36(2015), DOI:10.17221/704/2014-PSE

[RJC-5002/2018] 